\title{
Ion implantation in GaN at liquid-nitrogen temperature: Structural characteristics and amorphization
}

\author{
C. Liu, * B. Mensching, M. Zeitler, K. Volz, and B. Rauschenbach \\ Institut für Physik, Universität Augsburg, D-86135 Augsburg, Germany
}

(Received 25 September 1997)

\begin{abstract}
This paper deals with the results of a systematic investigation of damage generation and accumulation until amorphization induced by $180 \mathrm{keV} \mathrm{Ca}^{+}$and $\mathrm{Ar}^{+}$implantation in $\mathrm{GaN}$ films at liquid-nitrogen temperature. The structure of $\mathrm{GaN}$ films before and after implantation was characterized by Rutherford backscattering/ channeling, cross-sectional transmission electron microscopy, and high-resolution x-ray diffraction. The asimplanted GaN films exhibits an expanded lattice. Its texture was determined by pole figure measurement. An amorphous component has been found after $\mathrm{Ca}^{+}$implantation at doses not less than $3 \times 10^{14} \mathrm{~cm}^{-2}$. This suggests that $\mathrm{Ca}^{+}$implantation for $p$-type doping be carried out below this dose, in order to avoid unrecoverable structural damage and to achieve better transport properties. On the other hand, implantation with higher doses is generally needed to compensate for the native electron background of $\mathrm{GaN}$ and to realize $p$-type reversal. This conflict uncovers the essential difficulty for $p$-type doping of $\mathrm{GaN}$ by ion implantation. The maximum damage concentration exists in a depth of $100 \mathrm{~nm}$ below the surface, which corresponds to the mean projected range, and broadens gradually towards surface and greater depth with increasing ion fluence. The thresholds for the amorphization of $\mathrm{GaN}$ films are revealed to be $6 \times 10^{15} \mathrm{~cm}^{-2}$ for both $\mathrm{Ca}^{+}$and $\mathrm{Ar}^{+}$ implantation. The amorphization mechanism is discussed and the accumulation of amorphous clusters seems to be the reason for the collapse of GaN crystalline. [S0163-1829(98)02904-X]
\end{abstract}

\section{INTRODUCTION}

The technique of ion implantation is extremely attractive for the fabrication of $\mathrm{GaN}$ and related III-V compound devices because it can introduce a well-defined impurity concentration at a designed zone. To date, some progress has been made in this field such as $p$ - and $n$-type doping ${ }^{1-3}$ and electrical isolation ${ }^{3-5}$ by selective ion implantation as well as device fabrication. ${ }^{6}$ However, this technique is still far away from application in processing GaN-based semiconductor devices, primarily owing to ion-beam-induced lattice disorder, which deteriorates the electrical and optical properties. Although the research on $\mathrm{GaN}$ is in the ascendant, there remains little understanding about the implant damage buildup, removal and their effects on the transport properties of $\mathrm{GaN}$ devices. So far there are only a few papers, which demonstrate damage generation due to $\mathrm{Si}^{7,8}{ }^{7} \mathrm{Mg},{ }^{8}$ and $\mathrm{Zn}$ (Ref. 9) ion implantation as well as $\mathrm{Si}^{+}$and $\mathrm{Mg}^{+}$damage residual after high-temperature annealing. 8,10

No contribution deals with the structural nature of $\mathrm{Ca}$ doped GaN films, even though it was supposed to be a potentially superior shallow acceptor in $\mathrm{GaN}$ considering $d$-electron core relaxation effects. ${ }^{11}$ Therefore, more work in both theory and experiment will be necessary to get a reasonable picture of this important area. On the other side, $\mathrm{Ar}$ is an electrically inert element, and its atom mass is almost equal to that of $\mathrm{Ca}$. The comparison of the structural characteristics between $\mathrm{Ar}^{+}$- and $\mathrm{Ca}^{+}$-implanted $\mathrm{GaN}$ films helps to understand the influence of implantation-induced damage on the electrical properties of the doped GaN.

Another aim of this work is to lay a good foundation for the following recrystallization study. It is well known that to completely activate the implanted dopants in Si requires only an annealing temperature range of $550-600{ }^{\circ} \mathrm{C}$ if a continuous amorphous layer induced by ion bombardment has been formed. However, higher temperatures $800-1000{ }^{\circ} \mathrm{C}$ are necessary to remove the compensating point and line defects if the sample is heavily damaged but not amorphous. ${ }^{12-14}$ Along this line, it is worthwhile examining whether this is suitable for the doping of GaN films, because they may be degraded during postannealing at temperatures over $900{ }^{\circ} \mathrm{C} .{ }^{15-18}$ For this reason, it is of interest to determine the conditions under which a crystalline $\mathrm{GaN}$ film is rendered amorphous by ion implantation. In this paper we present characteristics of damage buildup and conditions for the amorphization of GaN films.

\section{EXPERIMENT}

The wurtzite GaN films used in this experiment are 530 and $600 \mathrm{~nm}$ thick, respectively. They were epitaxially grown on (0001)-oriented sapphire substrates with a diameter of two inches by gas-source molecular-beam epitaxy. ${ }^{19}$ The former was used for $\mathrm{Ca}^{+}$implantation and the latter for $\mathrm{Ar}^{+}$ implantation. Both kinds of ions with energy of $180 \mathrm{keV}$ were homogeneously implanted in the GaN films, respectively, in the dose range from $5 \times 10^{12}$ to $1 \times 10^{16} \mathrm{~cm}^{-2}$ at liquid-nitrogen $\left(L \mathrm{~N}_{2}\right)$ temperature. The current density was varied between 0.2 and $0.8 \mu \mathrm{A} / \mathrm{cm}^{2}$. To avoid channeling implantation, the incident beam direction was $7^{\circ}$ off the specimen normal. After implantation, Rutherford backscattering/channeling (RBS/C) analyses using $2.5 \mathrm{MeV}$ ${ }^{4} \mathrm{He}^{2+}$ ions were carried out to determine the damage profiles. The structure and orientational alignment were characterized by x-ray diffraction (XRD) measurements with a four-circle goniometer. Using an eulerian cradle the pole figures were measured at a fixed detector position $2 \theta_{h k l}$ by 


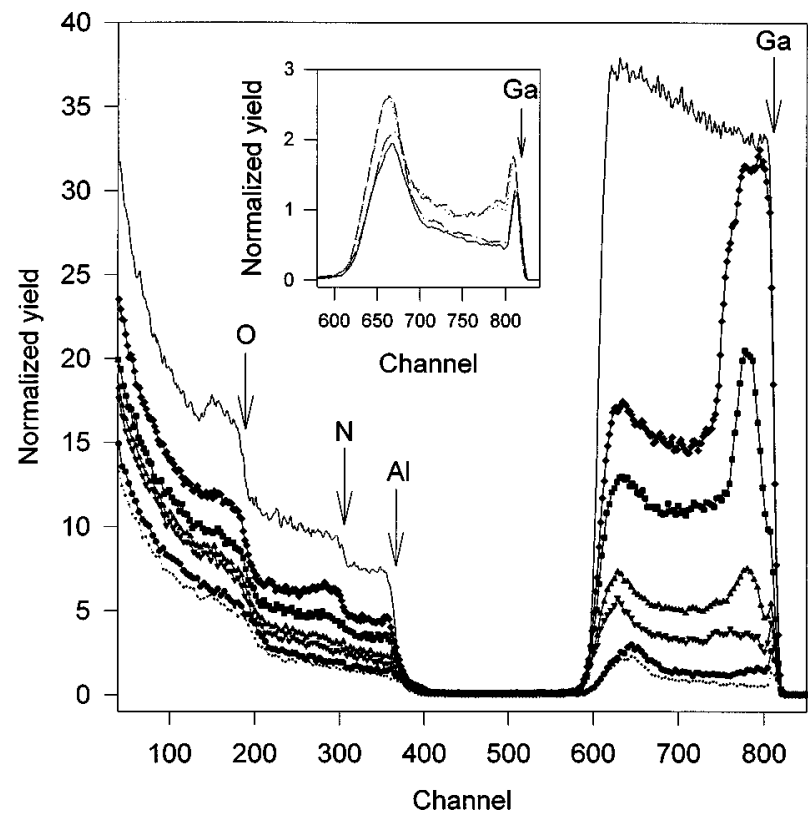

FIG. 1. [0001]-oriented RBS/C spectra $\left(2.5 \mathrm{MeV},{ }^{4} \mathrm{He}^{2+}\right)$ illustrating the damage buildup in $\mathrm{GaN}$ films for $180 \mathrm{keV} \mathrm{Ar}^{+}$implantation at $L \mathrm{~N}_{2}$ temperature with different doses: unimplanted (...), $5 \times 10^{13} \mathrm{~cm}^{-2} \quad\left(-\mathbf{O}_{-}\right), \quad 5 \times 10^{14} \mathrm{~cm}^{-2} \quad\left(-\boldsymbol{\nabla}_{-}\right), \quad 1 \times 10^{15} \mathrm{~cm}^{-2}$ $\left(-\boldsymbol{\Delta}_{-}\right), 3 \times 10^{15} \mathrm{~cm}^{-2}(-\mathbf{-}-), 6 \times 10^{15} \mathrm{~cm}^{-2}(--)$ ), and random (-). The inset shows a part of the backscattering spectra, containing only the information about $\mathrm{Ga}$ atoms at lower doses: unimplanted (-), $1 \times 10^{12} \mathrm{~cm}^{-2}$ (dashed dotted line), $5 \times 10^{12} \mathrm{~cm}^{-2}$ (dotted line), and $1 \times 10^{13} \mathrm{~cm}^{-2}$ (dashed line).

rotating the deposited layer around an axis normal (azimuthal angle $\Phi=0^{\circ}-360^{\circ}$ ) and parallel (polar angle $\chi$ $=5^{\circ}-85^{\circ}$ ) to the $\mathrm{GaN}$ substrate. The step widths were $1^{\circ}$. Selected samples were examined by cross-sectional transmission electron microscopy (XTEM) at an acceleration voltage of $300 \mathrm{kV}$. The samples for XTEM were prepared by conventional techniques involving $\mathrm{Ar}^{+}$sputtering as the last preparation step.

\section{RESULTS AND DISCUSSION}

Figure 1 shows [0001]-aligned and random backscattering spectra of the GaN films implanted with different $\mathrm{Ar}^{+}$doses at $L N_{2}$ temperature. It demonstrates the whole process of damage generation and accumulation until amorphization as a function of the ion dose. With the increase of $\mathrm{Ar}^{+}$fluence, a damage peak arises in the channeling spectra (around channel 780, which corresponds to a depth of about $100 \mathrm{~nm}$ below the surface). When the dose exceeds $1 \times 10^{15} \mathrm{~cm}^{-2}$, this peak grows up more quickly, accompanied by a broadening towards the surface and greater depth, and reaches the random level at the dose of $6 \times 10^{15} \mathrm{~cm}^{-2}$. This means that a closed amorphized layer is formed. Another feature in Fig. 1 is the change of the surface peak in the channeling spectra. It decreases gradually with increasing fluence and disappears almost at the dose of $3 \times 10^{15} \mathrm{~cm}^{-2}$, as the buried damage layer expands towards the surface. This is an indication of the collapse of the surface crystal structure. The inset in Fig. 1 illustrates the damage generation in the low dose range. It magnifies the high-energy portion of the channeling spectra, which contains only the information about $\mathrm{Ga}$ atoms. The

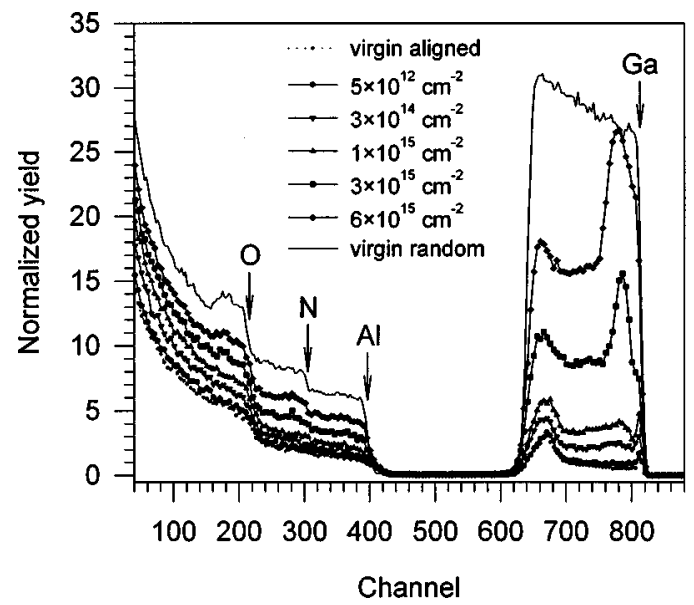

FIG. 2. [0001]-oriented RBS/C spectra $\left(2.5 \mathrm{MeV},{ }^{4} \mathrm{He}^{2+}\right)$ illustrating the damage buildup in $\mathrm{GaN}$ films for $180 \mathrm{keV} \mathrm{Ca}^{+}$implantation with different doses at $L \mathrm{~N}_{2}$ temperature.

channeling spectrum for the dose of $1 \times 10^{12} \mathrm{~cm}^{-2}$ coincides almost with that of the pure material. Furthermore, one can hardly distinguish the color variance of the GaN film after implantation at this dose. Until the dose reaches 5 $\times 10^{12} \mathrm{~cm}^{-2}$ the channeling spectra of both implanted and unimplanted films do not differ significantly. Therefore, the dose of $5 \times 10^{12} \mathrm{~cm}^{-2}$ should be regarded as the critical dose for the generation of stable damages that can be detected by $\mathrm{RBS} / \mathrm{C}$.

The damage buildup for $\mathrm{Ca}^{+}$implantation is displayed in Fig. 2. A similar progress as for $\mathrm{Ar}^{+}$implantation is shown. One can notice again that the dose of $5 \times 10^{12} \mathrm{~cm}^{-2}$ is necessary to generate damage detectable by RBS/C. Moreover, implantation with the dose of $6 \times 10^{15} \mathrm{~cm}^{-2}$ leads to amorphization. Thus, the thresholds for amorphization of $\mathrm{GaN}$ films are proven to be $6 \times 10^{15} \mathrm{~cm}^{-2}$ for both $\mathrm{Ca}^{+}$and $\mathrm{Ar}^{+}$ implantation with the energy of $180 \mathrm{keV}$ at $L \mathrm{~N}_{2}$ temperature.

Figure 3 illustrates the dependence of the normalized minimum yield $\chi_{\min }$ of the [0001] channeling on the implantation doses. It demonstrates the progress of amorphization induced by $\mathrm{Ca}^{+}$and $\mathrm{Ar}^{+}$implantation at $L \mathrm{~N}_{2}$ temperature.

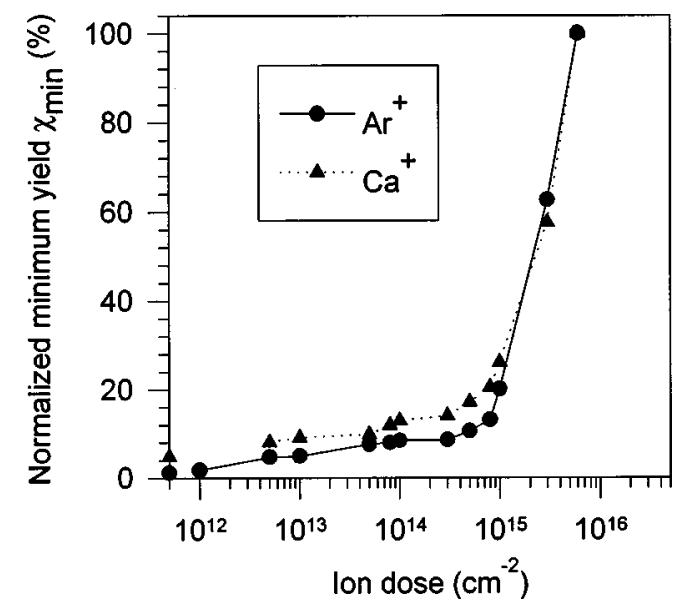

FIG. 3. Normalized minimum backscattering yield $\chi_{\min }$ taken from [0001]-oriented channeling spectra for $180 \mathrm{keV} \mathrm{Ca}^{+}-$and $\mathrm{Ar}^{+}$-implanted $\mathrm{GaN}$ at $L \mathrm{~N}_{2}$ temperature. The values for two pure samples are plotted at the longitudinal axis. 
The $\chi_{\min }$ values of the pure films drawn at the longitudinal axis are 1.2 and $4.9 \%$ corresponding to $\mathrm{Ar}^{+}$and $\mathrm{Ca}^{+}$implantation, respectively. This implies a good quality of the MBE as-grown samples. With increasing ion dose, $\chi_{\min }$ increases slowly up to the dose of $3 \times 10^{14} \mathrm{~cm}^{-2}$ in both cases. When the dose is in excess of $8 \times 10^{14} \mathrm{~cm}^{-2}$, both $\chi_{\text {min }}$ rise drastically and reach random level at $6 \times 10^{15} \mathrm{~cm}^{-2}$. One can find that the damage induced by $\mathrm{Ar}^{+}$bombardment at the dose of $3 \times 10^{15} \mathrm{~cm}^{-2}$ exceeds that of $\mathrm{Ca}^{+}$. This is consistent with the results of the implantation at room temperature. ${ }^{20}$

The depth profiles of the displaced atoms have been calculated from the measured RBS/C spectra using an iterative algorithm ${ }^{21}$ and are displayed in Fig. 4(a). An atomic density of GaN of $8.79 \times 10^{22} \mathrm{~cm}^{-3}$ was assumed [dotted line in Fig. 4(a)]. If the density of the displaced atoms after implantation reaches this level, the amorphous phase is formed. The $\mathrm{Ar}^{+}$ projected range and nuclear energy deposition in $\mathrm{GaN}$ have been simulated by TRIM90 (Ref. 22) and TRIDYN (Ref. 23), respectively. The results are also plotted in Fig. 4(a) for comparison. The curve drawn with the broken line represents the distribution of the ion range and the dash-dot-dot curve indicates the distribution of the nuclear energy deposition. Obviously, the buried damage layer centers around the maximum of the ion range distribution rather than around the peak of the nuclear energy deposition. The shape of the distribution of the displaced atoms is very similar to that of nuclear energy deposition. After implantation with 6 $\times 10^{15} \mathrm{Ar}^{+} / \mathrm{cm}^{2}$ the displaced atom density in a surface layer of $160 \mathrm{~nm}$ reaches the amorphous level. This means that a closed amorphous layer has been formed. It can be deduced that amorphization process starts in the region of the mean projected range ( $\sim 100 \mathrm{~nm}$ below the surface), progressing to the surface and greater depth with the increase of ion fluence. Figures 4(b) and 4(c) show, respectively, the XTEM bright and dark field micrographs for a sample that has been implanted by $6 \times 10^{15} \mathrm{Ar}^{+} / \mathrm{cm}^{-2}$ at $L \mathrm{~N}_{2}$ temperature, i.e., the sample is amorphized. Each of them consists of three parts: an amorphous surface layer with a thickness of $165 \mathrm{~nm}$, in which many Ar bubbles can be clearly observed, a damage layer extending to a depth of $240 \mathrm{~nm}$ below the surface, and the undamaged layer. Comparing the damage depth profile in Fig. 4(a) and the XTEM images in Figs. 4(b) and 4(c), one can conclude that they coincide exactly with each other.

Figure 5 shows the selected area electron diffraction (SAED) pattern taken from the surface of the $\mathrm{Ar}^{+}$-implanted GaN film $\left(180 \mathrm{keV}, 6 \times 10^{15} \mathrm{~cm}^{-2}\right)$ at $L \mathrm{~N}_{2}$ temperature. The amorphous ring can be clearly observed, which proves again that after $\mathrm{Ar}^{+}$irradiation at the dose of $6 \times 10^{15} \mathrm{~cm}^{-2}$ the $\mathrm{GaN}$ film is rendered amorphous.

Figure 6 illustrates the XRD spectra of the GaN (0002) peak before and after $\mathrm{Ca}^{+}$implantation with different doses at $L N_{2}$ temperature. The unimplanted film exhibits a very sharp (0002) peak with a full width at half maximum (FWHM) less than $0.06^{\circ}$. The smaller peak at $34.61^{\circ}$ originates from cubic $\mathrm{GaN}(111)$, which has a lattice constant of $4.5 \AA .{ }^{24}$ After implantation, a new peak on the left side of the (0002) peak appears. It grows up and shifts towards smaller angles with increasing fluence. Expansion of GaN crystal lattice due to ion implantation accounts for this phenomenon and is confirmed by TEM results. ${ }^{25}$ The extent of the lattice expansion depends on the defect concentration, which in-

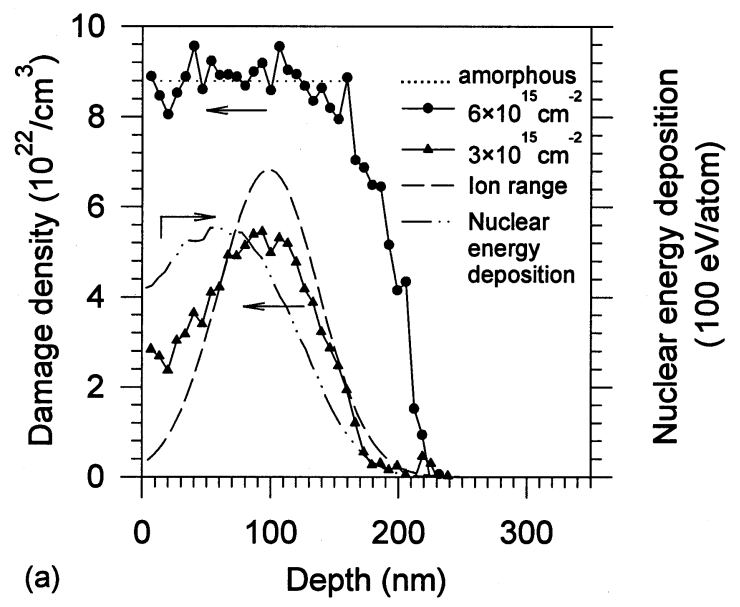

(b)

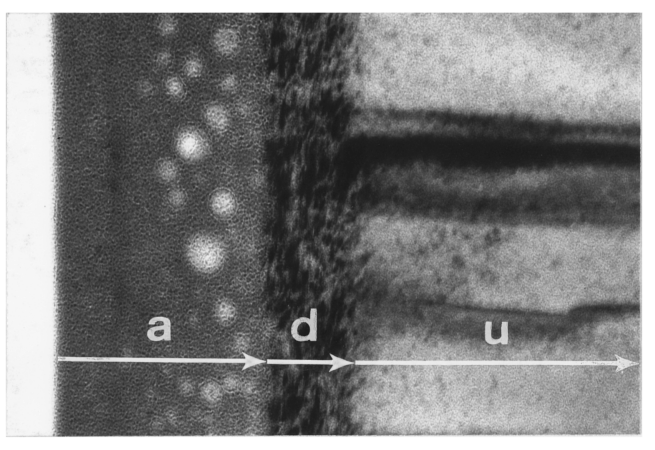

(c)

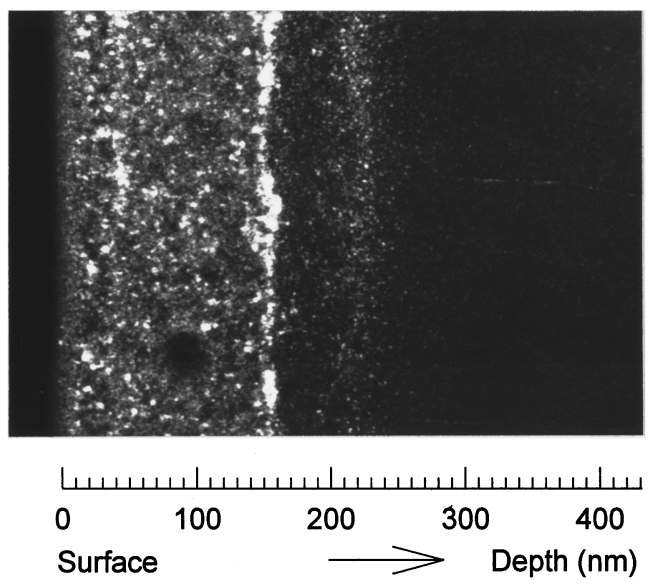

FIG. 4. The damage distribution in GaN implanted with 180 $\mathrm{keV} \mathrm{Ar}{ }^{+}$at $L \mathrm{~N}_{2}$ temperature as measured by (a) RBS/C depth profile. $180 \mathrm{keV} \mathrm{Ar}^{+}$projected range (broken line) and nuclear energy deposition (dash-dot-dot line) simulated, respectively, by TRIM90 and TRIDYN are presented for comparison. The dotted line shows the atomic density of $\mathrm{GaN}\left(8.79 \times 10^{22} \mathrm{~cm}^{-3}\right)$. (b) XTEM bright field micrograph, and (c) XTEM dark field micrograph. The sample for TEM observation was implanted with 6 $\times 10^{15} \mathrm{Ar}^{+} / \mathrm{cm}^{2}$. Both XTEM images show an amorphous layer $a$, a deeper damage band $d$, and the undamaged layer $u$.

creases synchronously with the ion dose. Hence, increasing intensity of the new peak is the consequence. However, it has been found that an amorphous phase arises at the dose of $3 \times 10^{14} \mathrm{~cm}^{-2}$ (see Fig. 7). After that the new peak gradually shrinks with the rapid development of the amorphous component and finally collapses into an amorphous peak when the dose reaches the threshold of $6 \times 10^{15} \mathrm{~cm}^{-2}$. Even 


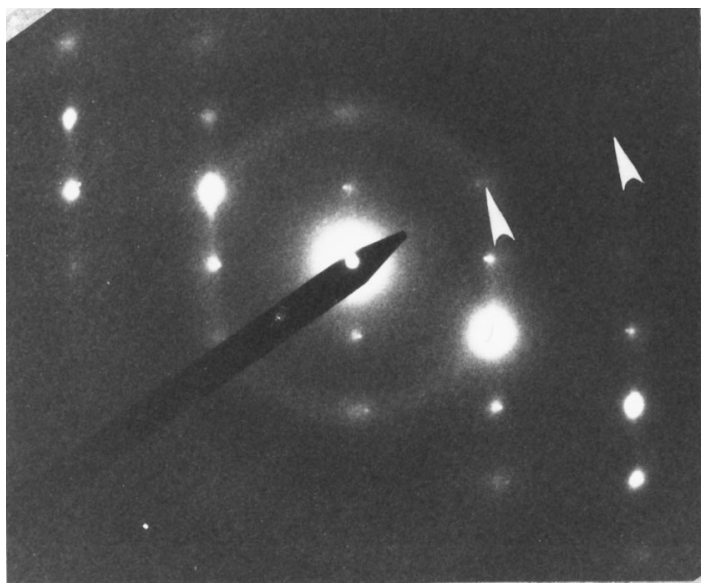

FIG. 5. Selected area electron diffraction pattern of the $\mathrm{Ar}^{+}$-implanted GaN sample $\left(180 \mathrm{keV}, 6 \times 10^{15} \mathrm{~cm}^{-2}\right)$ at $L \mathrm{~N}_{2}$ temperature. The amorphous ring (indicated by the arrows) is visible.

though a higher dose (e.g., $8 \times 10^{15}$ or $\left.1 \times 10^{16} \mathrm{~cm}^{-2}\right)$ is implanted, the amorphous peak is almost unchanged. Thus, XRD results testify once again that the dose of 6 $\times 10^{15} \mathrm{~cm}^{-2}$ is the critical dose for the amorphization of $\mathrm{GaN}$ films at $L \mathrm{~N}_{2}$ temperature. By the way, it is also interesting to observe the amorphization of the cubic GaN (111) peak with increasing $\mathrm{Ca}^{+}$dose.

Figure 6 shows also that the diffraction peaks are partially overlapped, i.e., a more detailed analysis should be performed by refinement of the spectra. In Fig. 7 an example is given by fitting the raw data of the XRD spectrum for the sample implanted with $3 \times 10^{14} \mathrm{Ca}^{+} / \mathrm{cm}^{2}$ at $L \mathrm{~N}_{2}$ temperature. The fitting program performs, in the sense of least squares, by a function of the following type: $f(x)=P_{1}(x)$ $+P_{2}(x)+\cdots+P_{i}(x)+\cdots+P_{m}(x)+B(x)$, where $m$ is the

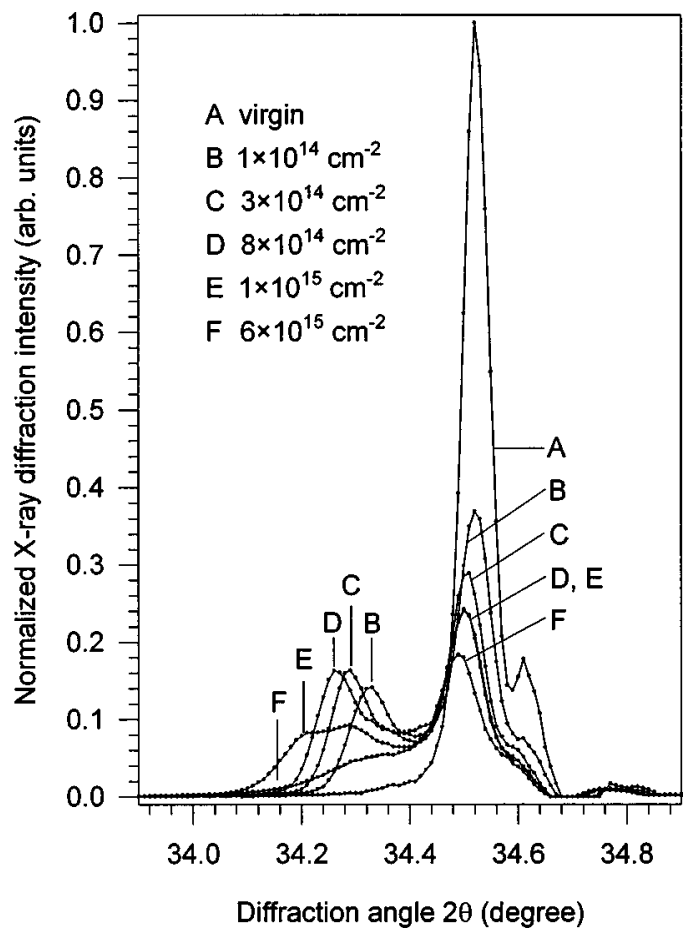

FIG. 6. Normalized GaN (0002) XRD spectra after $180 \mathrm{keV}$ $\mathrm{Ca}^{+}$implantation with different doses at $L \mathrm{~N}_{2}$ temperature.

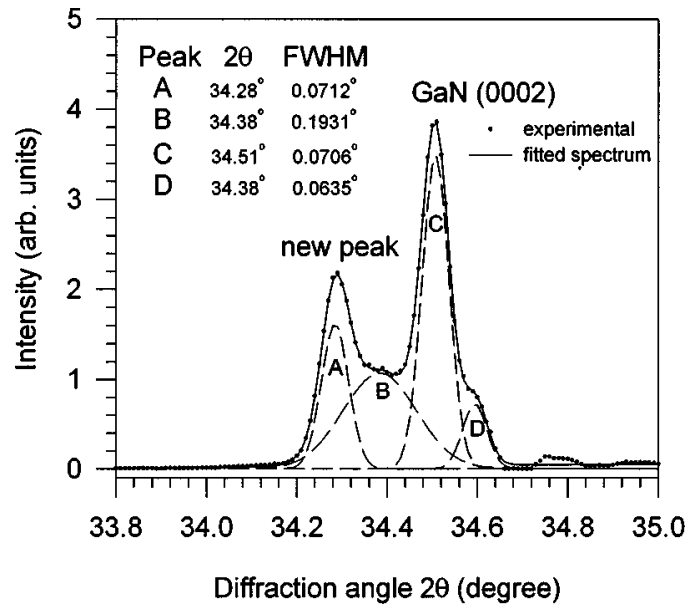

FIG. 7. XRD spectrum and its fitting results for the GaN sample doped with $180 \mathrm{keV}, 3 \times 10^{14} \mathrm{Ca}^{+} / \mathrm{cm}^{2}$. The inset table shows the

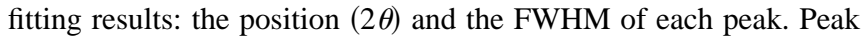
$A$, the expanded $\mathrm{GaN}$ (0002) lattice; peak $B$, amorphous component; peak $C$, the undamaged $\mathrm{GaN}$ (0002) peak after implantation; and peak $D$, the small cubic $\mathrm{GaN}$ (111) peak.

number of peaks and $B$ is the continuous background, which is assumed to be, locally, a straight line. The peaks $P_{i}, i$ $=1,2, \ldots$, and $m$ are supposed of the Gaussian shape. The result of the fitting is a set of parameters specifying the background and the peaks (intensity, $2 \theta$ position and FWHM) of the given type as well as the fitting error. The fitting of four Gaussian peaks which are named $A, B, C$, and $D$, respectively, was adopted for this spectrum and the result is drawn in Fig. 7. The relative error between measured and calculated intensities is less than $1.3 \times 10^{-4} \%$. Peak $A$ originates from the Ca-doped $\mathrm{GaN}$ layer, which indicates an expanded (0002) planar spacing. Peak $B$ lies exactly at the position of the amorphous peak, therefore, it should be regarded as the amorphous component. Peak $C$ coincides with the virgin (0002) peak, which implies it comes from the unimplanted GaN. Peak $D$ corresponds to the small peak of the cubic $\mathrm{GaN}$ (111). We have also fitted this spectrum using three peaks, i.e., ignoring peak $B$ (the amorphous component), and found that the relative error becomes much larger (4.14\%). It is quite evident, thus, that the amorphous component should be taken into account. In addition, when the dose was increased from $1 \times 10^{14}$ to $3 \times 10^{14} \mathrm{Ca}^{+} / \mathrm{cm}^{2}$, the XRD pattern in the $2 \theta$ region from 34.35 to $34.45^{\circ}$ (between the two peaks) varies greatly, i.e., the slope changes from positive to negative. This implies a substantial variance has taken place. Therefore, the amorphous component arises at the dose of $3 \times 10^{14} \mathrm{Ca}^{+} / \mathrm{cm}^{2}$ should be the proper explanation. Turning back to Fig. 6, one can sum up the situation at a glance that the amorphous component arises at the dose of 3 $\times 10^{14} \mathrm{Ca}^{+} / \mathrm{cm}^{2}$, dominates at $1 \times 10^{15} \mathrm{Ca}^{+} / \mathrm{cm}^{2}$ and develops into an stable amorphous peak at $6 \times 10^{15} \mathrm{Ca}^{+} / \mathrm{cm}^{2}$.

$\mathrm{X}$-ray pole figure measurements were performed to measure the texture of $\mathrm{GaN}$ in the direction of [0002]. Three pole figures have been measured for comparison: the pole figure of the new peak, and the pole figures of the (0002) peak before and after $\mathrm{Ca}^{+}$implantation. It has been found that there is no difference among these three pole figures except the different intensities. This means that the new peak has the same texture as the (0002) peak. Hence, it can be con- 


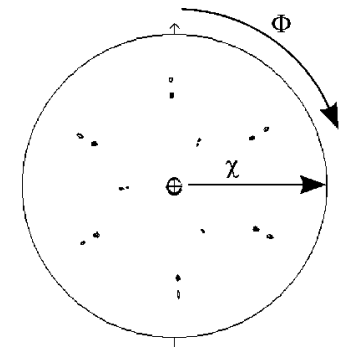

(a)

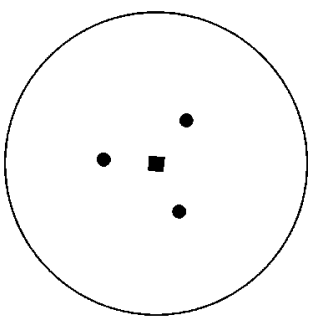

(b)
FIG. 8. (a) The (0002) pole figure of the new peak [the expanded $\mathrm{GaN}$ (0002) lattice] for the sample implanted with $180 \mathrm{keV}$, $3 \times 10^{14} \mathrm{Ca}^{+} / \mathrm{cm}^{2}$ at $L \mathrm{~N}_{2}$ temperature. (b) The simulated (0002) pole figure of $\mathrm{GaN}$ film grown epitaxially on $c$-plane sapphire.

cluded that the new peak originates from the expanded (0002) lattice in the implanted layer. $\mathrm{Ca}^{+}$implantation in $\mathrm{GaN}$ leads to a lattice expansion rather than a formation of a new phase. Figure 8(a) demonstrates the measured texture of the new peak for the sample implanted with 3 $\times 10^{14} \mathrm{Ca}^{+} / \mathrm{cm}^{2}$ at $L \mathrm{~N}_{2}$ temperature. The theoretical prediction for the (0002) pole figure for a perfect $\mathrm{GaN}$ crystalline on $c$-plane sapphire substrate is displayed in Fig. 8(b). The $\mathrm{GaN}(0002)$ pole lies in the center of the pole figure. At $\chi$ $=38.24^{\circ}$ the $\mathrm{Al}_{2} \mathrm{O}_{3}(104)$ substrate peaks appear. The experimental consists with the theoretical. The outer two hexagonal peaks in Fig. 8(a) are supposed to be twins of the GaN (0002). Their intensities are much weaker than that of the (0002) peak.

After implantation, rapid thermal annealing (RTA) at $1150{ }^{\circ} \mathrm{C}$ for $15 \mathrm{sec}$ was performed to remove the implant damage and to activate the doped acceptors. It has been found that the implant damage can be well removed after the processing of RTA, if the implantation dose is lower than $3 \times 10^{14} \mathrm{Ca}^{+} / \mathrm{cm}^{2},{ }^{20,26}$ the dose at which the amorphous component arises. The amorphization of $\mathrm{GaN}$ develops very slowly up to the dose of $8 \times 10^{14} \mathrm{Ca}^{+} / \mathrm{cm}^{2}$ (see Fig. 6) because of dynamic beam annealing. ${ }^{25}$ However, when the dose exceeds $1 \times 10^{15} \mathrm{Ca}^{+} / \mathrm{cm}^{2}$, the tendency of amorphization is increased more and more rapidly. Great residual damage remains in the doped GaN films and no significant reduction of damage can be observed even after $1150{ }^{\circ} \mathrm{C}$ activation. ${ }^{26}$ Therefore, $\mathrm{Ca}^{+}$implantation at low temperature for $p$-type doping should be carried out at a dose below 3 $\times 10^{14} \mathrm{~cm}^{-2}$ in order to avoid unrecoverable structural damage and to achieve better transport properties. On the other hand, since unimplanted $\mathrm{GaN}$ films have generally a very high background electron concentration (about 1 $\times 10^{17} \mathrm{~cm}^{-3}$ for a MBE as-grown GaN film), a high dose of acceptors $\left(\geqslant 1 \times 10^{15} \mathrm{~cm}^{-2}\right)$ is needed to be implanted for the realization of $p$-type reversion. Unfortunately, this high dose implantation introduces unrecoverable damage, and the doped $p$-type carriers are easily trapped and compensated by the radiation defects, resulting in a less effective activation even after a high-temperature annealing. Consequently $p$-type doping in $\mathrm{GaN}$ is difficult to realize by ion implantation.

As far as the mechanism of amorphization is concerned, Morehead and Crowder ${ }^{27}$ proposed a model that hypoth- esized that each ion impinging on the target produces a cylindrical amorphous core. Amorphization occurs when such damage cores completely fill the area of the target. According to this semiquantitative model, the critical dose for amorphization decreases with increasing ion mass and is constant at sufficiently low temperature. Gibbons ${ }^{28}$ has modified this model by assuming that an amorphous layer can also be produced by the overlap of damaged, nonamorphous regions associated with individual damage clusters. In the case of $\mathrm{GaN}$, point defects dominate at low ion doses. They provide appropriate nucleation sites for the formation of localized amorphous clusters in which the free energy of the defective crystal exceeds that of the amorphous phase. As the dose increases, local amorphous nucleation can be produced by the overlap of individual defect, dislocation or damage cluster. This view is verified by the fact that the amorphous component was found at the dose of $3 \times 10^{14} \mathrm{Ca}^{+} / \mathrm{cm}^{2}$ by the XRD measurement. At this time, the GaN lattice can still maintain its basic integrity, containing only isolated amorphous nuclei. However, once the amorphous nuclei forms, it grows, through damage accumulation, into the underlying crystalline regions with further irradiation. On the other hand, the defects induced by the implantation at $L \mathrm{~N}_{2}$ temperature can be thought of in a "frozen" state. Thus, the possibility of formation of secondary defects is greatly increased. The amorphous nuclei can grow up by overlapping with each other or with adjacent secondary defects such as clusters and loops. At the threshold dose the amorphous nuclei are closely connected all together, and the GaN crystalline collapses into an amorphous phase.

\section{CONCLUSION}

We have systematically studied the characteristics of the damage buildup and amorphization by $\mathrm{Ca}^{+}$and $\mathrm{Ar}^{+}$implantation in $\mathrm{GaN}$ at $L \mathrm{~N}_{2}$ temperature. RBS/C, XTEM, and XRD analyses give a consistent picture of the structural variance after the implantation. It has been found that an amorphous component arises at the dose of $3 \times 10^{14} \mathrm{Ca}^{+} / \mathrm{cm}^{2}$. In order to avoid unrecoverable radiation damage, $\mathrm{Ca}^{+}$implantation for $p$-type doping should be performed below this dose. Amorphization takes place at first at the depth of the mean projected range $(\sim 100 \mathrm{~nm})$ and then extends towards both directions of the surface and greater depth. The threshold doses for the amorphization of $\mathrm{GaN}$ films are revealed to be $6 \times 10^{15} \mathrm{~cm}^{-2}$ in the cases of both $\mathrm{Ca}^{+}$and $\mathrm{Ar}^{+}$implantation at $L \mathrm{~N}_{2}$ temperature. Accumulation of the amorphous zone seems to be the mechanism for the amorphization of GaN.

\section{ACKNOWLEDGMENTS}

We would like to thank Siemens Corporate Research and Development for supplying the MBE-grown GaN films, and W. Reiber, W. Brückner, and D. Donimierski for technical support. One of the authors (C.L.) acknowledges the German Academic Exchange Service (DAAD) for financial support of his stay at the Universität Augsburg. This work was partly supported by Deutsche Forschungsgemeinschaft (DFG). 
*Permanent address: Department of Physics, Wuhan University, Wuhan 430072, People's Republic of China. Electronic address: chang.liu@physik.uni-augsburg.de

${ }^{1}$ M. Rubin, N. Newman, J. S. Chan, T. C. Fu, and J. T. Ross, Appl. Phys. Lett. 64, 64 (1994).

${ }^{2}$ J. C. Zolper, R. G. Wilson, S. J. Pearton, and R. A. Stall, Appl. Phys. Lett. 68, 1945 (1996).

${ }^{3}$ S. J. Pearton, C. B. Vartuli, J. C. Zolper, C. Yuan, and R. A. Stall, Appl. Phys. Lett. 67, 1435 (1995).

${ }^{4}$ S. C. Binari, H. B. Dietrich, G. Kelner, L. B. Rowland, K. Doverspike, and D. K. Wickenden, J. Appl. Phys. 78, 3008 (1995).

${ }^{5}$ C. B. Vartuli, S. J. Pearton, C. R. Abernathy, J. D. MacKenzie, and J. C. Zolper, J. Vac. Sci. Technol. B 13, 2293 (1995).

${ }^{6}$ J. C. Zolper, R. J. Shul, A. G. Baca, R. G. Wilson, S. J. Pearton, and R. A. Stall, Appl. Phys. Lett. 68, 2273 (1996).

${ }^{7}$ H. H. Tan, J. S. Williams, J. Zou, D. J. H. Cockayne, S. J. Pearton, and R. A. Stall, Appl. Phys. Lett. 69, 2364 (1996).

${ }^{8}$ N. Parikh, A. Suvkhanov, M. Lioubtchenko, E. Carlson, M. Bremser, D. Bray, R. Davis, and J. Hunn, Nucl. Instrum. Methods Phys. Res. B 127/128, 463 (1997).

${ }^{9}$ S. Strite, P. W. Epperlein, A. Dommann, A. Rockett, and R. F. Broom, in Gallium Nitride and Related Materials, edited by R. D. Dupuis, J. A. Edmond, F. A. Ponce, and S. Nakamura, MRS Symposia Proceedings Vol. 395 (Materials Research Society, Pittsburgh, 1996), p. 795.

${ }^{10}$ J. C. Zolper, H. H. Tan, J. S. Williams, J. Zou, D. J. H. Cockayne, S. J. Pearton, M. H. Crawford, and R. F. Karlicek, Jr., Appl. Phys. Lett. 70, 2729 (1997).

${ }^{11}$ S. Strite, Jpn. J. Appl. Phys. 33, L699 (1994).

${ }^{12}$ B. L. Crowder and F. F. Morehead, Appl. Phys. Lett. 14, 313 (1969).

${ }^{13}$ B. L. Crowder, J. Electrochem. Soc. 117, 671 (1970).

${ }^{14}$ L. A. Christel, J. F. Gibbons, and T. W. Sigmon, J. Appl. Phys. 52, 7143 (1981).
${ }^{15}$ R. Groh, G. Gerey, L. Bartha, and J. I. Pankove, Phys. Status Solidi A 26, 353 (1974).

${ }^{16}$ J. Karpinski, J. Jun, and S. Porowski, J. Cryst. Growth 66, 1 (1984).

${ }^{17}$ N. Newman, J. T. Ross, and M. D. Rubin, Appl. Phys. Lett. 62, 1242 (1993).

${ }^{18}$ C. B. Vartuli, S. J. Pearton, C. R. Abernathy, J. D. MacKenzie, E. S. Lambers, and J. C. Zolper, J. Vac. Sci. Technol. B 14, 3523 (1996).

${ }^{19}$ H. Riechert, R. Averbeck, A. Graber, M. Schienle, U. Strauß, and H. Tews, in III-V Nitride, edited by F. A. Ponce, T. D. Moustakas, I. Akasaki, and B. A. Monemar, MRS Symposia Proceedings Vol. 449 (Materials Research Society, Pittsburgh, 1997), p. 149.

${ }^{20}$ B. Mensching, C. Liu, B. Rauschenbach, K. Kornitzer, and W. Ritter, Proceedings of the European Materials Research Society/ International Conference on Advanced Materials 1997, Strasbourg, France, June 16-20, 1997 [Mater. Sci. Eng. B (to be published)].

${ }^{21}$ L. C. Feldman, J. W. Mayer, and S. T. Picraux, Materials Analysis by Ion Channeling (Academic, New York, 1992), p. 117.

${ }^{22}$ J. P. Biersack and L. G. Haggmark, Nucl. Instrum. Methods 174, 257 (1980).

${ }^{23}$ W. Eckstein, Computer Simulation of Ion Solid Interactions (Springer, New York, 1991).

${ }^{24}$ T. D. Moustakas, T. Lei, and R. J. Molnar, Physica B 185, 36 (1993).

${ }^{25}$ C. Liu, B. Mensching, K. Volz, and B. Rauschenbach, Appl. Phys. Lett. 71, 2313 (1997).

${ }^{26}$ C. Liu, B. Mensching, and B. Rauschenbach (unpublished).

${ }^{27}$ F. F. Morehead, Jr. and B. L. Crowder, Radiat. Eff. 6, 27 (1970).

${ }^{28}$ J. F. Gibbons, Proc. IEEE 60, 1062 (1972). 